\title{
REFLECTION ELECTRON ENERGY LOSS SPECTROSCOPY OF ALKALI METALS ON SILICON
}

\author{
Ch. Kleint and S.M. A Bd El-Halim* \\ Sektion Physik, Universität Leipzig \\ Linné str. 5, (O)-7010 Leipzig, Germany \\ (Received May 21, 1991; in revised version August 1, 1991)
}

\begin{abstract}
In an extended introduction studies of alkali adsorption on clean silicon surfaces are shortly reviewed and recent achievements are outlined. The main part describes our investigations of lithium and potassium adsorption by reflection electron energy loss spectroscopy (REELS). Beside (electronic) valence electron excitations also core losses of both silicon and these alkali metals were observed in the ionization loss spectroscopy mode (ILS). Additional information has been obtained by Auger electron spectroscopy (AES) and measurements of work function changes (WFC). The spectra of $\mathrm{Li}$ and $\mathrm{K}$ adsorption on the $\mathrm{Si}(100)$ plane show considerable differences which will be discussed in detail. By simulation of the REEL potassium spectra within the density of states (DOS) model using the $\mathrm{Si}(100) 2 \times 1 \mathrm{~K}$ DOS by $\mathrm{R}$. Ramirez the origin of the 8.4 and $12.5 \mathrm{eV}$ loss peaks can be traced to band structure features. In addition the known $\mathrm{K}$ peaks at 18.1, 20 and $22 \mathrm{eV}$ are confirmed and their behaviour with increasing primary energy $E_{\mathrm{p}}$ was investigated. While the $\mathrm{K} 3 p-\mathrm{K} 4 s$ transition corresponding to the $18.1 \mathrm{eV}$ loss increases with $E_{\mathrm{p}}$, the dipole-forbidden K $3 p-\mathrm{K} 4 p$ transition (20 eV) decreases. Shifts in the loss energy of these peaks as well as in the core loss energies at 295 and $296.8 \mathrm{eV}$ are observed and explained by charge transfer. PACS numbers: 73.20.-r, 79.20.Fv, 79.20.Hx
\end{abstract}

\section{Introduction}

The adsorption of alkali metals on metals or semiconductors has been extensively studied but continues to be a prominent area of surface research. The interest comes from the unique physical properties of these simple model interfaces which allow to test ideas of chemisorption, bonding and metallization. A strong mutual interaction between alkali adatoms also leads to one- or two-dimensional adsorbate layers and fundamental results on commensurate and incommensurate

*Permanent address: Department of Physics, El-Minia University, El-Minia, Egypt. 
adparticle phases and their transitions [1]. In addition, the alkali metals cause large changes in surface properties, frequently with technological effects [2, 3]. This is also true for semiconductors where the negative electron affinity of cathodes [4] and the "catalytic" activity of alkali metals in the silicon oxydation and nitridation processes [5] should be emphasized. In a "classical picture" of Langmuir alkali metals adsorbed on metals were thought to be strongly ionized at least at small coverages while with increasing coverage the (electron) charge transfer to the substrate is diminished. Recent theoretical and experimental investigations revealed the contrary "dressed-atom picture" [6] where the adatom charge is insensitive to coverage and changes in the polarization of the dipoles account for the decreasing work function. A similar change in view seems now to take place for the alkali adsorption on semiconductor surfaces. Batra and coworkers proposed from numerous calculations mainly an ionic adlayer model for the $\mathrm{Si}(100) 2 \times 1$ surface which leads for instance to a metallic $(\Theta=1)$ or semiconducting $(\Theta=2)$ surface for adsorbed sodium [7]. Soukiassian et al. [8] pointed out recently, however, that the alkali metal/silicon bonding is covalent leading to an adsorbate rather than substrate metallization. Such a polarized silicon-alkali metal bond is also a result of local density functional calculations for $\mathrm{Si}(100) 2 \times 1 \mathrm{~K}$ by Ishida and Terakura [9] but we refer to the invited paper of Soukiassian for an extensive discussion of these fundamental questions. In what follows we restrict ourselves on alkali metals on silicon and give a short survey on selected properties.

From early studies of caesium adsorption on the silicon (100) surface one would assume that potassium atoms deposited on $\mathrm{Si}(100)$ are chemisorbed between the outward tilted Si dimers and that a 0.5 monolayer (ML) coverage forms one-dimensional rows of atoms along the [110] direction. This structural model was first proposed by Levine [10] for the similar $\mathrm{Si}(100)$ Cs adsorption system. Low-energy electron diffraction (LEED) confirmed this assumption by showing that upon $\mathrm{K}$ deposition no pattern change occurred but only some redistribution of the intensities of the $\mathrm{Si}(100) 2 \times 1$ reconstruction [11, 12]. Qualitatively this geometry seems to be consistent with all experimental data and theoretical calculations [13-18], although the quantitative value of the $\mathrm{K}-\mathrm{Si}$ bond length, which has important implications on the electronic properties, is a subject of theoretical debate [13]. From the calculation performed on the Si(100) $2 \times 1 \mathrm{~K}$ surface, Ciraci and Batra found the K-Si bond length to be $2.29 \AA$ [19]. Kasowski and Tsai, using an $a b$ initio total energy calculation with a pseudo-function method on the same system, found the $\mathrm{K}-\mathrm{Si}$ bond length to be $3.30 \AA$ [20] while, very recently, $\mathrm{Ye}$ Ling et al. [21], using an $a b$ initio self-consistent total energy calculation for the $\mathrm{Si}(100) 2 \times 1 \mathrm{~K}$ interface found $3.22 \AA$ for two different adsorption sites.

By Auger electron spectroscopy (AES) Oellig and Miranda [15] proved a layer-by-layer growth of potassium on $\mathrm{Si}(111)$ and $\mathrm{Si}(100)$ surfaces at room temperature. Greene et al. [22] obtained activation energies for desorption of $\mathrm{K}$ and $\mathrm{Na}$ atoms from $\mathrm{Si}$ surfaces. Tochihara [11] and Aruga et al. [16] predicted a one-dimensional adsorbed structure of $\mathrm{K}$ or $\mathrm{Cs}$ on the $\mathrm{Si}(100)$ surface from measurements of plasmon dispersion.

AES has frequently been used in many studies of adsorption layer formation, where Auger intensities from adsorbates and from a substrate are plotted 
against coverage. Since an isolated alkali metal atom has only one electron in its valence $s$ level it cannot undergo an Auger process involving two electrons that belong to the same valence level. When it is adsorbed, however, interatomic Auger or cross transitions between the alkali metal atom and the substrate possibly occur. If the valence level broadens to form a band, a so-called intraatomic transition will become allowed. By observing such transitions that occur just at the adsorbate-substrate interface, one can get information on the local charge state around the adsorbate.

Recent observations by Tochihara [11] on the $\mathrm{Si}(100) \mathrm{K}$ surface indicated that the alkali atoms on semiconductor surfaces lead practically to the same features as observed on transition metals. The work function decreases rapidly at submonolayer coverages $(\Theta \ll 1)$, and later, concomitant with the onset of an electron energy-loss peak at $\sim 2 \mathrm{eV}$, it decreases slowly without passing through a minimum. The growing intensity of the REELS peak with increasing $\Theta$ was attributed to a collective excitation of the "metallic" electrons of the overlayer. Tochihara [11] also found a shift of the $\mathrm{K} 3 p$ loss with increasing coverage from $19.4 \mathrm{eV}$ at $\Theta=0.1 \mathrm{ML}$ to $18.6 \mathrm{eV}$ at $\Theta=0.25 \mathrm{ML}$. In addition a peak at $4 \mathrm{eV}$ appeared which is shifted with increasing $\mathrm{K}$ coverage to $2 \mathrm{eV}$. Aruga et al. [16] observed the $\mathrm{Si}(100) 2 \times 1 \mathrm{~K}$ plasmon peak at $1.95 \mathrm{eV}$ and a shift with the detector angle.

There are very few loss measurements of the $\mathrm{Si}(100) 2 \times 1 \mathrm{Li}$ system. Tochihara and Murata [23] found a loss peak at $13 \mathrm{eV}$ which they ascribed to a lithium silicide. They observed also the $\mathrm{Si}(100) 2 \times 1 \mathrm{~K}$ peak at $2.0 \mathrm{eV}$.

In what follows we report on our experimental results to characterize further the adsorption of potassium and lithium on the $\mathrm{Si}(100) 2 \times 1$ surface. Auger electron spectroscopy (AES), electron energy loss spectroscopy in the reflection mode (REELS or ELS for shortness) and work function changes (WFC) were used to provide a firmer basis for the discussion of these interesting systems.

\section{Experimental}

The investigations were carried out in a stainless steel UHV system with ion getter pump and Ti evaporator which achieved a base pressure of $3 \times 10^{-10} \mathrm{hPa}$ after $2 \times 10 \mathrm{~h}$ degassing at $250^{\circ} \mathrm{C}$. A stand-by oil diffusion pump station with liquid $\mathrm{N}_{2}$ traps served for a quick start and easy degassing of the ion getter pump. The $5 \times 20 \mathrm{~mm}^{2}$ samples were cut from a [100] oriented $p$-type Si wafer with a. $15 \mu \mathrm{m}$ $n$-type epitaxial layer $(0.2 \Omega \mathrm{cm})$. They were clamped together with a $1 \mathrm{~mm}$ thick $\mathrm{Si}$ substrate in a self-supported mounting. This allowed a micropyrometer (and vacuum) controlled heating by a direct current up to $1000^{\circ} \mathrm{C}$ and a slow return to room temperature (RT) in about 30 min thus establishing the condition for a $\operatorname{Si}(100) 2 \times 1$ surface.

Lithium and potassium were deposited on to the Si sample at room temperature by a resistive heated alkali dispenser source (S.A.E.S, Italy). The distance between source and sample was 6-8 $\mathrm{mm}$, the sources were degassed in a parking position for two hours which resulted in a vacuum improvement from $10^{-7} \mathrm{hPa}$ to $3 \times 10^{-10} \mathrm{hPa}$. The evaporation currents were 8.5 and $5.8 \mathrm{~A}$ for lithium and potassium, respectively. 
The spectra were taken with a LEED system and multichannel analyzer and the work function change (WFC) by the retarder method as described more detailed in Ref. [24]. The first derivative of the loss energy distribution was measured with $1 V_{p p}$ and the Auger spectra (1st derivative) with $10 V_{p p}$. The 2nd derivatives given in the figures were calculated. The signal to noise ratio for the clean silicon AES peak at $91 \mathrm{eV}$ was 10:1 at $150 \mathrm{eV}$. The modulation amplitude for oxygen and carbon was also $10 \mathrm{~V}_{\mathrm{pp}}$.

\section{Results}

\subsection{Li on the Si(100) surface}

The sample preparation and thickness of the deposited $\mathrm{Li}$ layer has been controlled by Auger spectroscopy. Using a primary energy of $E_{\mathrm{p}}=1 \mathrm{keV}$ we found six AE transitions of silicon at 106, 91, 74, 56, 44 and $34 \mathrm{eV}$. After $30 \mathrm{~s} \mathrm{Li}$ evaporation two Li peaks at 35 and $42 \mathrm{eV}$ appeared. Figure 1 shows that the $\mathrm{Si}$ $91 \mathrm{eV}$ peak decreases continuously up to $120 \mathrm{~s}$ while at that time the Li Auger peak to peak intensities already start into saturation. The $35 \mathrm{eV}$ peak even decreases somewhat with further $\mathrm{Li}$ deposition.

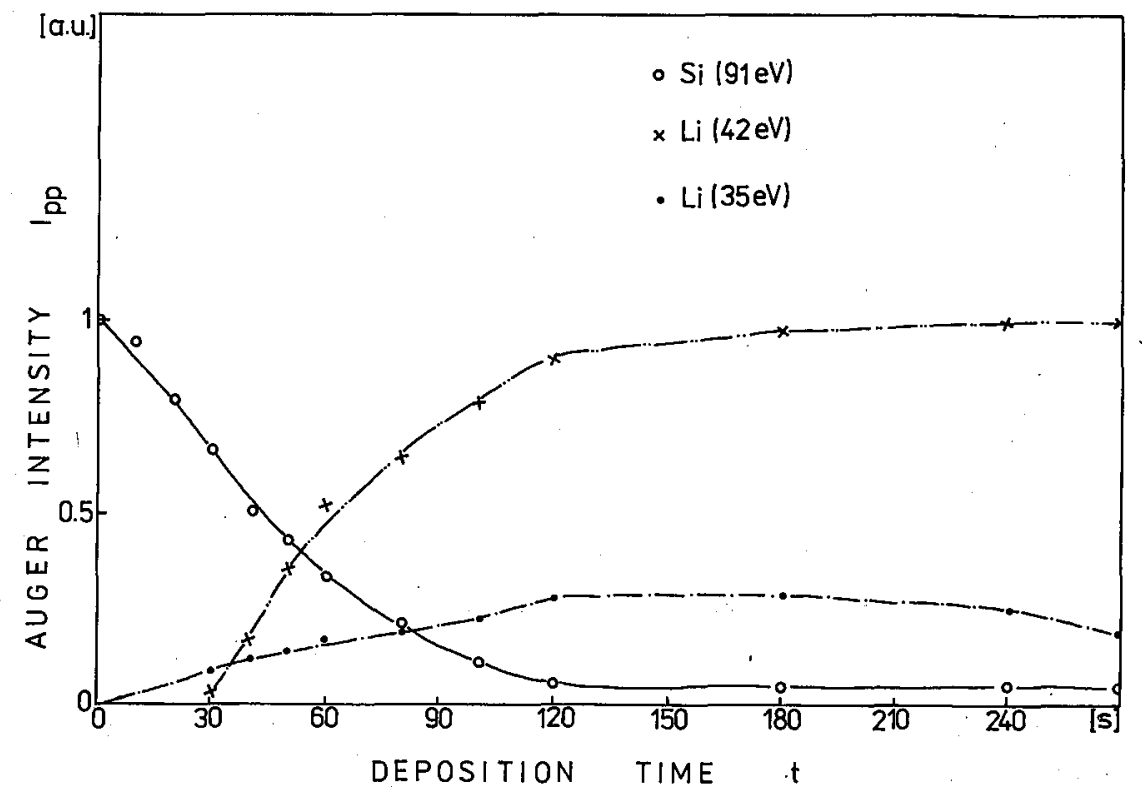

Fig. 1. Dependence of the peak to peak Auger intensity on the deposition time of lithium onto the $\mathrm{Si}(100)$ surface at room temperature.

In principle, Auger transitions of isolated $\mathrm{Li}$ atoms or ions are impossible due to the $\left(1 s^{2}, 2 s^{1}\right)$ configuration of lithium as the 3 rd element of the periodic table. 
Only with some interaction of adsorbed lithium in close neighbourhood leading to a common valence band or with the silicon-lithium bonding indicating a first stage of a compound, interatomic Auger or cross transitions will appear. This might explain the sharp onset of the $42 \mathrm{eV}$ peak at $30 \mathrm{~s}$. The $\mathrm{AE}$ spectra of clean solid lithium revealed a peak at $52 \mathrm{eV}$ [25] and those of $\mathrm{LiO}$ at $38 \mathrm{eV}$ [26]. We could not find by AES any oxygen or carbon contamination. Therefore we presume the $42 \mathrm{eV}$ peak to represent a $\mathrm{K}_{\mathrm{Li}} \mathrm{L}_{\mathrm{Li}} \mathrm{V}_{\mathrm{Si}}$ or $\mathrm{K}_{\mathrm{Li}} \mathrm{V}_{\mathrm{Si}} \mathrm{L}_{\mathrm{Li}}$ transition and the $35 \mathrm{eV}$ peak a $\mathrm{K}_{\mathrm{Li}} \mathrm{V}_{\mathrm{Si}} \mathrm{V}_{\mathrm{Si}}$ secondary transition. Nishigaki et al. [27] observed 42 and $35 \mathrm{eV} \mathrm{AE}$ peaks also with $\mathrm{Li}$ adsorption on the $\mathrm{Si}(111) 7 \times 7$ surface.

The results of three independent measurements of the work function change $\Delta \phi$ during $\mathrm{Li}$ deposition are shown in Fig. 2. While a rapid decrease by $2.32 \mathrm{eV}$

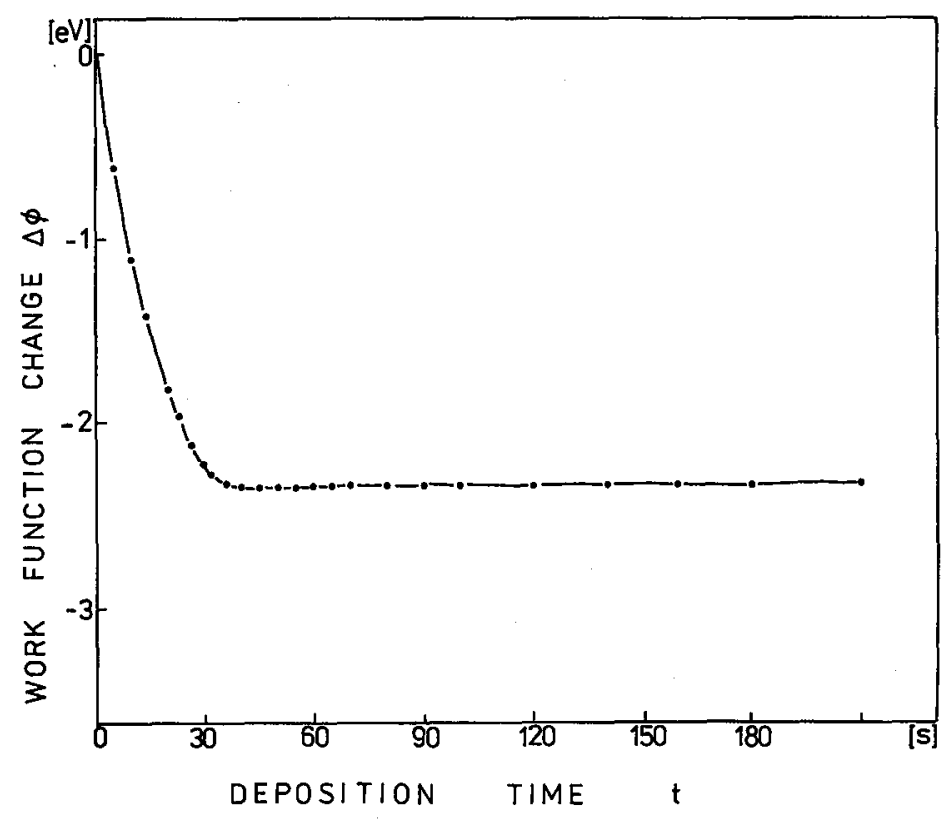

Fig. 2. Change of the work function during lithium deposition onto the $\mathrm{Si}(100)$ surface at room temperature.

appears already in the first $40 \mathrm{~s}$ a definite minimum is not observed and $\phi$ remains constant with further evaporation. For the clean metal the work function is known to be $\phi_{\mathrm{Li}}=2.93 \mathrm{eV}$ [28]. Assuming $\phi_{\mathrm{Si}}=4.85 \mathrm{eV}$ for the $n$-type silicon [29] we arrive at $\phi_{\mathrm{Si}-\mathrm{Li}}=2.53 \mathrm{eV}$ at $120 \mathrm{~s}$ deposition which is lower than the bulk value of lithium. Nishigaki [27] also observed $\Delta \phi=-2.3 \mathrm{eV}$ and Tochihara and Murata [23] found $\Delta \phi=-2.4 \mathrm{eV}$ and $-2.6 \mathrm{eV}$ with normal and very high coverages, respectively.

For a detailed characterization of the Li adsorption various electron energy loss spectra of the $\mathrm{Si}(100)$ plane were measured for a close succession of increasing coverages up to $300 \mathrm{~s}$ deposition (Fig. 3). In order to obtain high surface sensitivity 
a primary energy of $E_{\mathrm{p}}=80 \mathrm{eV}$ was used throughout. Starting with the clean
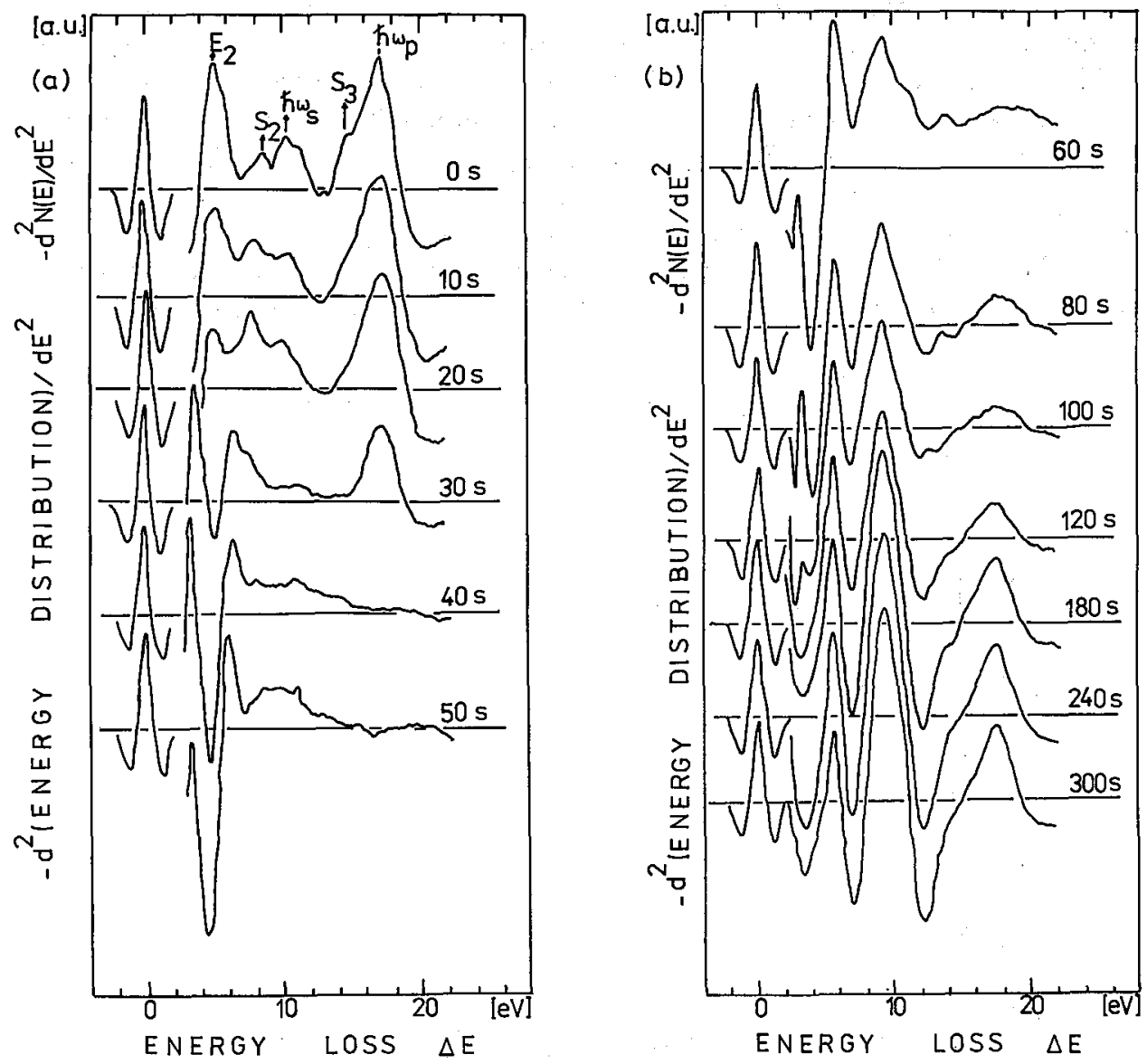

Fig. 3. Negative second derivative energy loss spectra of different coverages of lithium on the $\mathrm{Si}(100)$ surface at room temperature given by the deposition time. (Primary energy $E_{\mathrm{p}}=80 \mathrm{eV}$, primary peak height reduced by a factor of ten).

$\operatorname{Si}(100)$ surface, bulk and plasmon transitions $S_{2}, E_{2}$ and $\hbar \omega_{s}$ or $\hbar \omega_{p}$ decrease within the first $30 \mathrm{~s}$ of deposition while $S_{3}$ disappears already at $10 \mathrm{~s}$. Similar to the Auger peaks two new losses at 3.1 and $5.8 \mathrm{eV}$ appear at $30 \mathrm{~s}$. Unexpectedly, however, the $3.1 \mathrm{eV}$ loss decreases shortly afterwards to disappear finally at $120 \mathrm{~s}$. Figure 4 displays the concomitant increase of the 5.8 and $9.6 \mathrm{eV}$ peaks which is accompanied also by a $17.2 \mathrm{eV}$ loss.

\subsection{Potassium on the Si(100) surface}

We describe first the $\mathrm{AE}$ and work function measurements being a basis for the coverage determination and, in addition, a check of possible contaminations. 


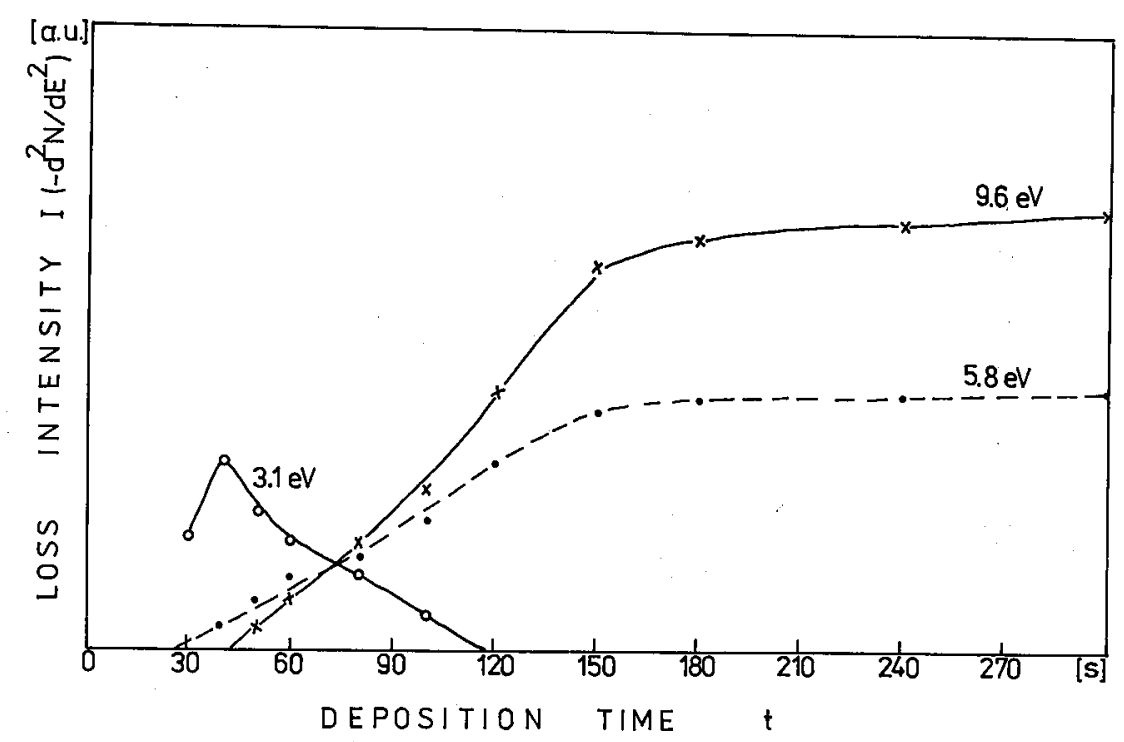

Fig. 4. Dependence of the loss peak intensities of Fig. 3 on the Li deposition time at room temperature.

The Auger spectra were obtained at a vacuum of about $10^{-9} \mathrm{hPa}$ within a time interval of 0.5 to $1 \mathrm{~min}$ per spectrum. Beside a small amount of oxygen neither other contaminations could be detected nor an AES peak shift with coverage. The Auger peak to peak intensities $I_{\mathrm{pp}}$ are given in Fig. 5. Four regions in the decreasing Si-LMM (91 eV) signal are observed, characterized by different slopes in the intensity versus deposition time plot. They are mirrored likewise by the increasing $\mathrm{K}-\mathrm{LMM}(252 \mathrm{eV})$ signal, the sharp bending points being located at $t_{1}=90 \mathrm{~s}, t_{2}=180 \mathrm{~s}, t_{3}=315 \mathrm{~s}$, and $t_{4}=405 \mathrm{~s}$ which we ascribe, according to Oellig and Miranda [15], to the completion of $0.5,1,1.5$ and 2 monolayers, respectively. No definite correspondences to these regions can be stated for the oxygen peak being very small and below $t_{1}$ near the sensitivity limit. Nevertheless, a definite increase in the oxygen signal with increasing $\mathrm{K}$ coverage is obvious. This might be explained by a rise of the oxygen sticking coefficient on the $K$ covered silicon surface (according to a possible formation of potassium oxide). Analogous observations were made by Surnev et al. [30] with the Ni(100)K system where the oxygen sticking coefficient also increases with $\mathrm{K}$ coverage. In the same direction point desorption energy measurements of $\mathrm{Cs}$ on the W(100) surface [31,32] where a decrease occurs with rising $C$ s coverage but an increase with additional oxygen adsorption.

Further, other Auger peaks appear at 79 and $64 \mathrm{eV}$ which we had also found with methanol adsorption on silicon [24] and ascribed to the silicon oxide phase. They are larger than the signal from $390 \mathrm{~s} \mathrm{~K}$ deposition onwards and similarly the oxygen peak exceeds the Si peak at about $410 \mathrm{~s}$ or two K monolayers. Presumably 


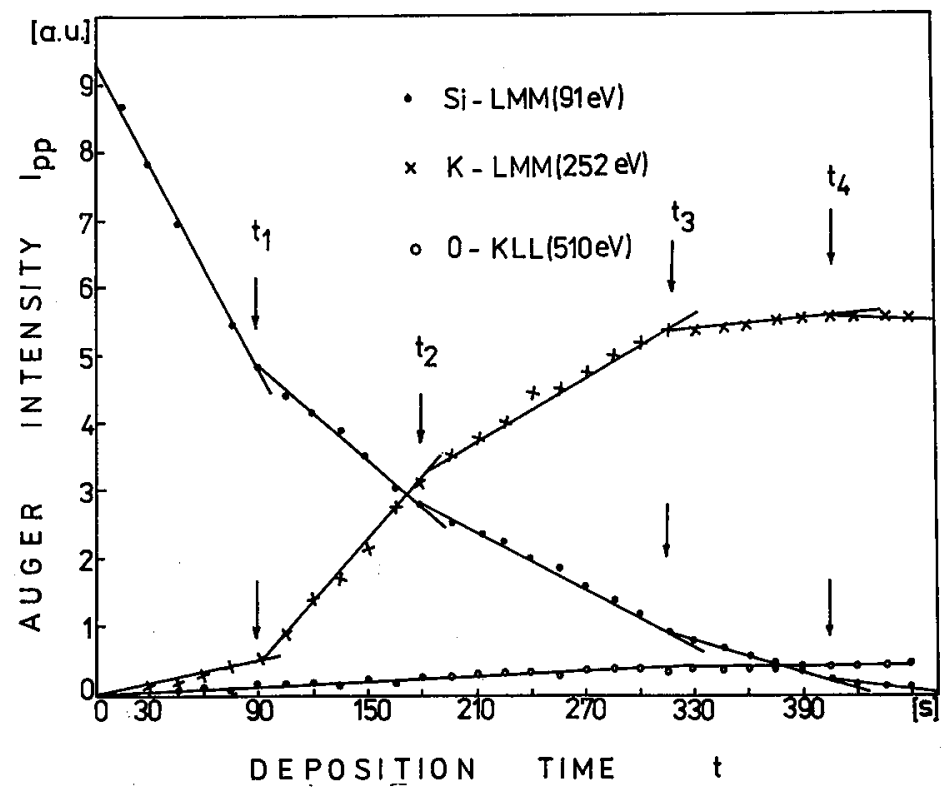

Fig. 5. Dependence of the Auger peak to peak intensity $I_{\mathrm{pp}}$ on the potassium deposition time for the $\mathrm{Si}(100)$ surface at room temperature. (Primary beam energy $1.1 \mathrm{keV}$ ).

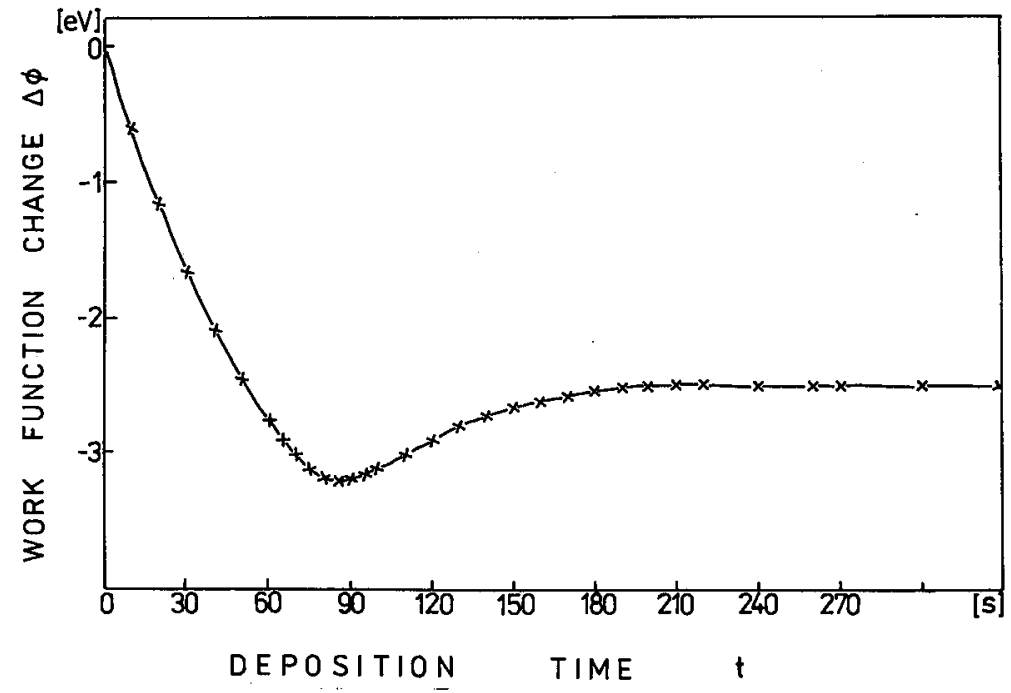

Fig. 6. Change of the work function during the potassium deposition onto the $\operatorname{Si}(100)$ surface at room temperature. 
for potassium coverages $\Theta_{\mathrm{K}}$ beyond 1.5 ML a further $\Theta_{\mathrm{K}}$ increase is only possible by some oxygen leading to Si-O-K bonds. The number of second layer $\mathrm{K}$ adatoms appears to grow with the number of oxygen atoms. Consequently the maximum $\mathrm{K}$ coverage at room temperature seems to be restricted to about two monolayers. In fact we observed a saturation of the $\mathrm{K}$ signal after $410 \mathrm{~s}$ deposition (corresponding to $13.6 \times 10^{14}$ atoms $/ \mathrm{cm}^{2}$ ). This is in agreement with the experiments of Oellig et al. [15] who found with continued $\mathrm{K}$ evaporation between " 2 and $2.5 \mathrm{ML}$ " only a small increase of the K AES signal.

The results of four measurements of the work function change $\Delta \phi$ are displayed in Fig. 6. A deep minimum with $\Delta \phi_{\min }=-3.2 \pm 0.1 \mathrm{eV}$ appears at $85 \mathrm{~s} \mathrm{~K}$ deposition and saturation is observed beyond $190 \mathrm{~s}$ with $\Delta \phi_{\mathrm{s}}=-2.5 \pm 0.03 \mathrm{eV}$. Assuming the $n$-type Si work function to be $4.7 \mathrm{eV}$ [33] we obtain the minimum $\mathrm{Si}(100) \mathrm{K}$ value to be $1.5 \mathrm{eV}$ which is in good agreement with other measurements compiled in Table I.

\section{TABLE I}

Compilation of $\mathrm{Si} / \mathrm{K}$ work function measurements.

\begin{tabular}{l|c|c|c|c}
\hline \hline System & $\phi_{\min }(\mathrm{eV})$ & $\phi_{\mathbf{s}}(\mathrm{eV})$ & $\Theta_{\min }(\mathrm{ML})$ & Ref. \\
\hline $\mathrm{Si}(100) \mathrm{K}$ & 1.7 & 2.2 & 0.5 & {$[15]$} \\
$200 \mathrm{~K}$ & & & & \\
$\mathrm{Si}(111) \mathrm{K}$ & 1.5 & 1.9 & 0.5 & {$[15]$} \\
$300 \mathrm{~K}$ & & & & \\
$\mathrm{Si}(100) \mathrm{K}$ & 1.7 & 1.9 & 0.5 & {$[34]$} \\
$\mathrm{Si}(100) \mathrm{K}$ & 1.37 & 1.5 & 0.5 & {$[35]$} \\
$\mathrm{Si}(100) \mathrm{K}$ & 1.5 & 2.2 & 0.5 & this work \\
$\mathrm{Si}(100) \mathrm{K}$ & 1.5 & 1.9 & $0.5-0.6$ & {$[36]$} \\
$\mathrm{Si}(100) \mathrm{K}$ & - & 2.6 & - & {$[11]$}
\end{tabular}

We now turn to the electron energy loss experiments. Because the potassium layers are sensitive to contamination from the residual gas atmosphere we restricted the measurements to a maximum of $10 \mathrm{~min} \mathrm{~K}$ deposition time. The spectra were recorded with the highest possible energy resolution by diminishing the modulation amplitude to $0.6 \mathrm{~V}_{\mathrm{pp}}$ to resolve the expected loss at about two $\mathrm{eV}$. The electron gun was switched off during the deposition. The difference spectra against the clean $\mathrm{Si}(100)$ surface for various $\mathrm{K}$ coverages are shown in Fig. 7. (The raw data had been treated by a five-fold application of an 8 points smoothing procedure and all curves are displayed to the same scale.)

The most important REELS result is the coverage dependent energy shift of some loss maxima. Because of the collective nature of the adsorbate plasmon loss it is only to be expected at coverages of at least 0.5 monolayer. The obtained loss (Fig. 7) at $2.4 \mathrm{eV}$ (shifting to $2.7 \mathrm{eV}$ ) can be attributed from about $t=$ $90 \mathrm{~s}(\Theta=0.5 \mathrm{ML})$ onwards to the excitation of the $\mathrm{K}$ overlayer plasmon but at smaller coverages another mechanism is responsible. Therefore to give details of the loss intensity dependence versus coverage would be meaningless. With increasing 

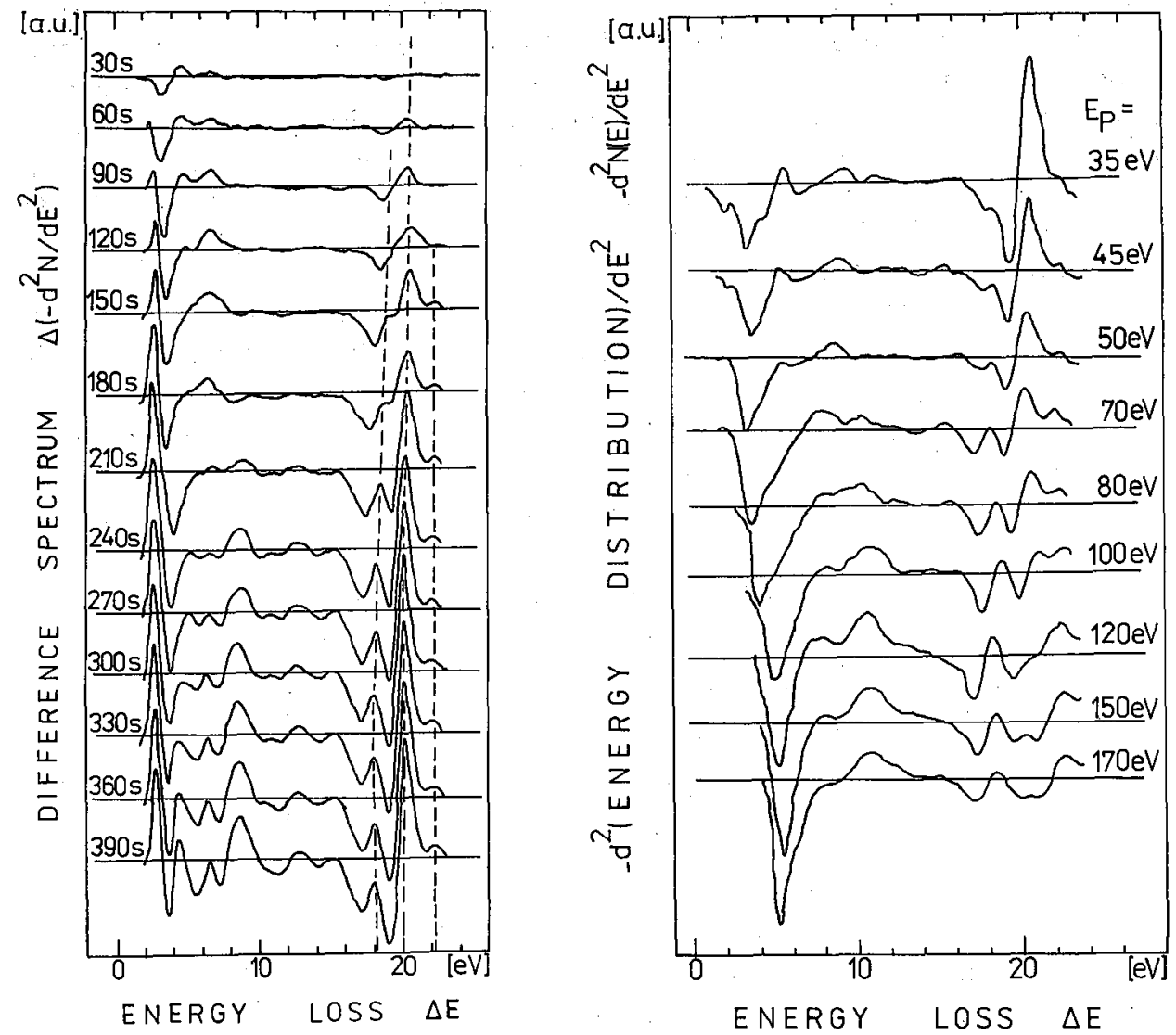

Fig. 7. Difference ELS spectra relative to the clean $\mathrm{Si}(100)$ surface with increasing potassium coverage given by the deposition time at room temperature.

Fig. 8. Doubly differentiated energy distribution of the Si(100) surface with a K layer corresponding to $180 \mathrm{~s}$ deposition time at room temperature.

coverage the peak energy is shifted from $2.4 \mathrm{eV}$ at $t=90 \mathrm{~s}(\Theta=0.5 \mathrm{ML})$ to $2.7 \mathrm{eV}$ at $t=180 \mathrm{~s}$ or $1 \mathrm{ML}$. The last energy is in agreement with the surface plasmon energy obtained for potassium metal namely $2.7 \pm 0.1 \mathrm{eV}$ [37]. According to Aruga et al. [16] the $\mathrm{Si}(100) 2 \times 1 \mathrm{~K}$ plasmon peak appears at $1.95 \mathrm{eV}$ and changes somewhat with the detector angle. The loss found at $4.3 \mathrm{eV}$ with coverages higher than $1 \mathrm{ML}(180 \mathrm{~s}$, Fig. 7) corresponds to the volume plasmon loss of the potassium layer. It appears at $4.6 \mathrm{eV}$ and is shifted to $4.3 \mathrm{eV}$ at a deposition of $390 \mathrm{~s}(2 \mathrm{ML})$. This peak is in agreement with the volume loss of potassium [37].

An advantage of the reflection EEL spectroscopy is the possibility to vary the energy $E_{\mathrm{p}}$ of the primary electron beam and to obtain in this way information on surface or bulk states and on excitation cross sections. Figure 8 is a compilation of $\mathrm{Si}(100) \mathrm{K}$ spectra with different $E_{\mathrm{p}}$ for a deposition time of $180 \mathrm{~s}$ i.e. about 1 
monolayer. Especially the losses at 20.5 and $18.7 \mathrm{eV}$ undergo considerable changes. These losses also shift with increasing coverage to smaller energies (cp. Fig. 7). We will discuss this behaviour in Sec. 4.2. Figure 9 shows the $\mathrm{K} 2 p$ losses at $E_{\mathrm{p}}=450 \mathrm{eV}$ with different $\mathrm{K}$ coverages on $\mathrm{Si}(100)$. At small depositions up to $30 \mathrm{~s}$ the two peaks at 295 and $296.8 \mathrm{eV}$ increase in intensity. The peak at $295 \mathrm{eV}$ is shifting to $294 \mathrm{eV}$ but remains constant from $90 \mathrm{~s}$ onwards.
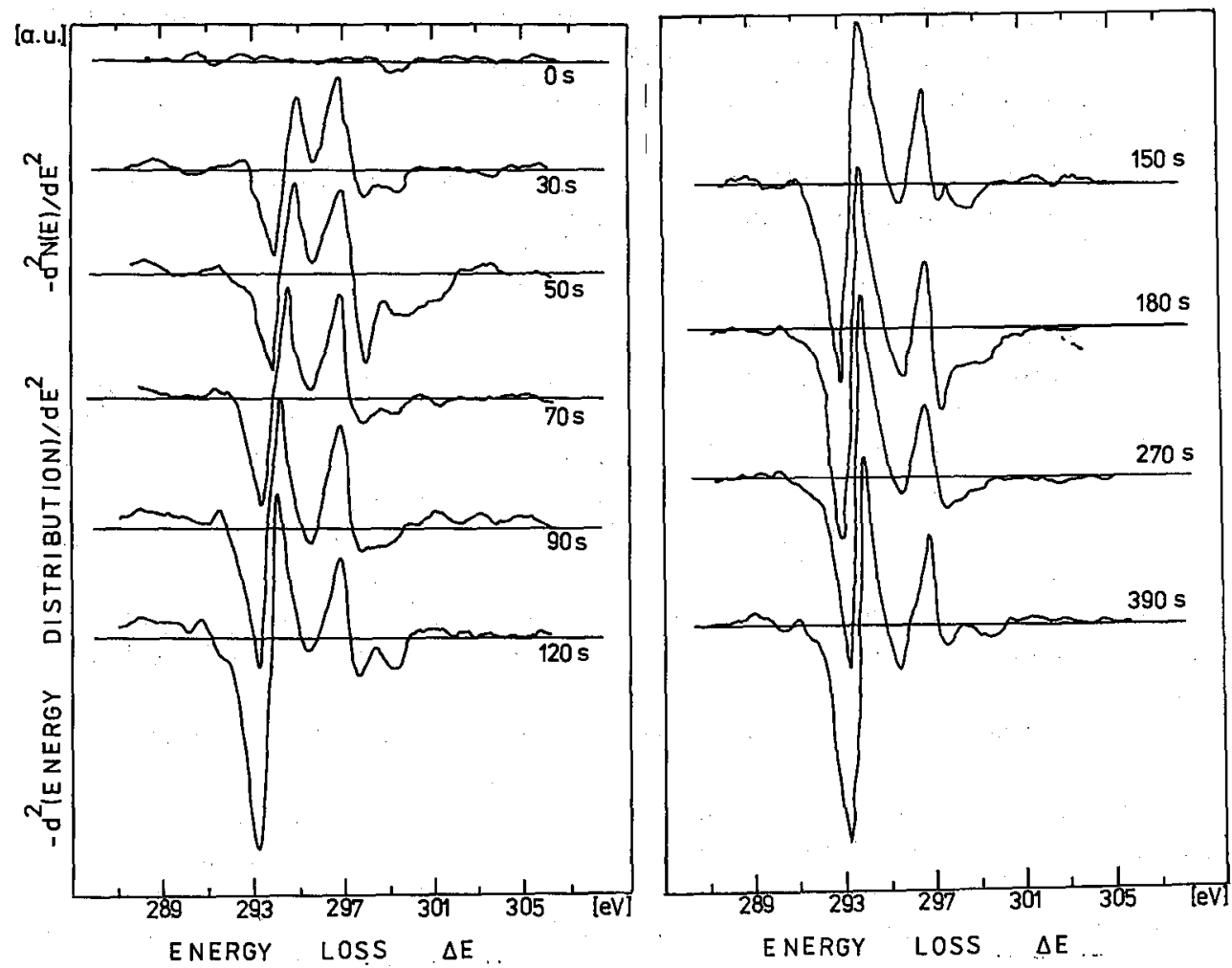

Fig. 9. K $2 p$ core loss spectra of the $\mathrm{Si}(100) \mathrm{K}$ system with increasing $\mathrm{K}$ coverages characterized by the deposition time at room temperature at a primary energy $E_{\mathrm{p}}=$ $450 \mathrm{eV}$.

\section{Discussion}

\subsection{The lithium bonding to the silicon surface}

In a layer of alkali metals on metal and semiconductor surfaces the overlayer plasmon (OLP) is excited by the electron beam hitting the surface [38-41] but this 
requires at least coverages of $0.5 \mathrm{ML}$. Kloos [37] reports on fast electron energy loss experiments with lithium (and other metals). Losses at 5.01 and $7.08 \mathrm{eV}$ are ascribed to the surface and volume plasmon, $\hbar \omega_{s}(\mathrm{Li})$ and $\hbar \omega_{p}(\mathrm{Li})$, respectively. Kunz [42] and Fellenzer [43] found 4.2 or $4.6 \mathrm{eV}$ and 7.12 or $8.0 \mathrm{eV}$ for the surface and volume plasmon of $\mathrm{Li}$ metal, respectively. Whatever the exact plasmon values are, they don't agree with the losses 5.8 or $9.6 \mathrm{eV}$ 'obtained in our experiments.

Usually approximate metal plasmon energies are already found in an alkali overlayer with the completion of the adsorbate monolayer or the growth of the second layer as for instance with sodium on the $\mathrm{Cu}(111)$ surface [44]. We suspect, therefore, that the peaks at 5.8 and $9.6 \mathrm{eV}$ correspond to a lithium silicide forming with further deposition after monolayer completion. Tochihara and Murata [23] ascribe also a peak found at $13 \mathrm{eV}$ to Li silicide formation where the different bulk plasmon energy might be due to another composition. The decreasing $\mathrm{Li}(35 \mathrm{eV})$ Auger intensity at higher deposition times (Fig. 1) seems to be in favour of a silicide growth.

The $3.1 \mathrm{eV}$ loss corresponds obviously to a transition from an occupied $\mathrm{Li}$ level to a silicon conduction band maximum.

\subsection{The potassium bonding to the silicon surface}

Excitations of the K $3 p$ core level are to be expected in the loss region up to $25 \mathrm{eV}$. According to the K $3 p$ binding energy we ascribe the (slightly shifting) loss maxima $19.2 \rightarrow 18.1 \mathrm{eV}$ and $20.5 \rightarrow 20.0 \mathrm{eV}$ to transitions from this level. Figure 10 shows that beside the energy shift also the intensity is changing considerably with coverage. They increase steeply with coverage but might not be resolvable at too small coverages. The shift of the $\mathrm{K} 3 p-4 s$ loss with coverage is largely due to the $\mathrm{K}$ initial state. (The loss measurements do not change the charge state of the adsorbate in contrast to photoemission.) Brodèn and Bonzel [45] found an analogous shift of the $\mathrm{K} 3 p$ binding energy of the $\mathrm{Fe}(100) \mathrm{K}$ system from 18.6 to $18.1 \mathrm{eV}$ by means of UPS investigations.

Tochihara [11] also observed a similar energy shift of the $\mathrm{K} 3 p$ loss from potassium on the $\mathrm{Si}(100)$ surface, namely from $19.4 \mathrm{eV}$ at $\Theta=0.1 \mathrm{ML}$ to $18.6 \mathrm{eV}$ at $\Theta=0.25 \mathrm{ML}$, and $18.1 \mathrm{eV}$ at higher coverages in accordance with the $\mathrm{K} 3 p$ binding energy. He, therefore, correlates the final state with the $\mathrm{K} 4 s$ level. The loss peak $20.5 \rightarrow 20.0 \mathrm{eV}$ is interpreted as a $\mathrm{K} 3 p-4 p$ transition. This view is supported by two observations. The energy difference of the loss maxima $(20.2 \mathrm{eV}-18.6 \mathrm{eV}=$ $-1.6 \mathrm{eV}$ ) at higher coverages ( $>180 \mathrm{~s}$ ) corresponds exactly to the optically determined $\mathrm{K} 4 s$ and $\mathrm{K} .4 p$ energy difference of the potassium atom (1.61 $\mathrm{eV},[46])$. The second observation is given by our loss intensity measurement versus the primary energy documented in Fig. 11. A K $3 p-4 p$ excitation should be forbidden because of $\Delta I=0$ according to the dipole selection rules. However, with electron energy loss spectroscopy a suspension of these rules is to be expected at small excitation energies as was shown by Ludeke and Koma [47] for GaAs and germanium. A plot (Fig. 11) of the primary energy dependence of the K $3 p-4 p$ and K $3 p-4 s$ intensities taken from the results of Fig. 8 in fact shows a considerable reduction in the $\mathrm{K}$ $3 p-4 p$ maximum with increasing $E_{\mathrm{p}}$. The intensity of the optical allowed K $3 p-4 s$ transition reveals a much smaller change. 


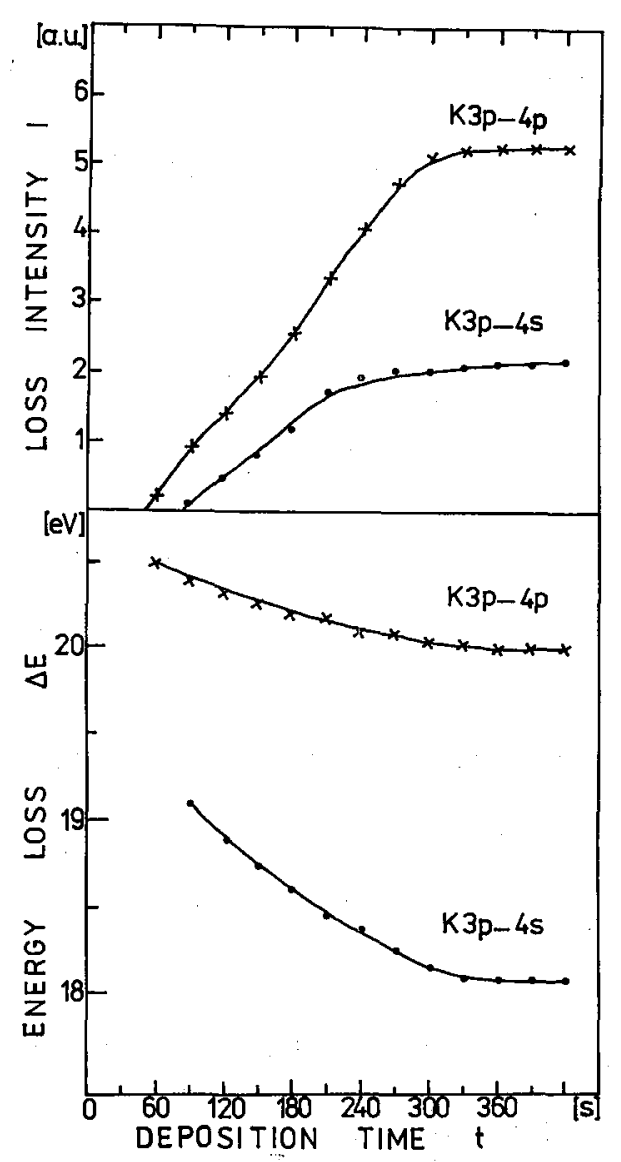

Fig. 10. Change of the loss intensity and loss energy of the transitions $\mathrm{K} 3 p-4 p$ and $\mathrm{K} 3 p-4 s$ with increasing $\mathrm{K}$ coverage on the $\mathrm{Si}(100)$ surface at room temperature given by the deposition time.

In this semilogarithmic plot the straight line representing the K $3 p-4 p$ transition consists of two parts with different slopes. The strong decrease (I, Fig. 11) accompanies the coming into force of the dipole selection rule. The weaker decrease of its part II is assigned to the transition into the $s$-part of the final state because a weak $s p$-hybridization should be assumed according to Muscat and Newns [48]. The $p$-type final state obviously does not play any role beyond $E_{\mathrm{p}} \geq 80 \mathrm{eV}$ because of the dipole selection rule.

The coverage dependent energy shift of the $\mathrm{K} 3 p-4 s$ loss by $1.1 \mathrm{eV}$ and the $\mathrm{K}$ $3 p-4 p$ loss by $0.5 \mathrm{eV}$ can be explained by the transition of the ionized $\mathrm{K}$ adparticles at small coverages into an approximately neutralized adlayer. The measured shift of the $\mathrm{K} 3 p-4 s$ loss corresponds to the difference in the optical excitation energies of the $\mathrm{K}$ ion $3 p-4 s$ transition $(20.2 \mathrm{eV})$ and the $\mathrm{K}$ atom transition $(18.8 \mathrm{eV})$ 


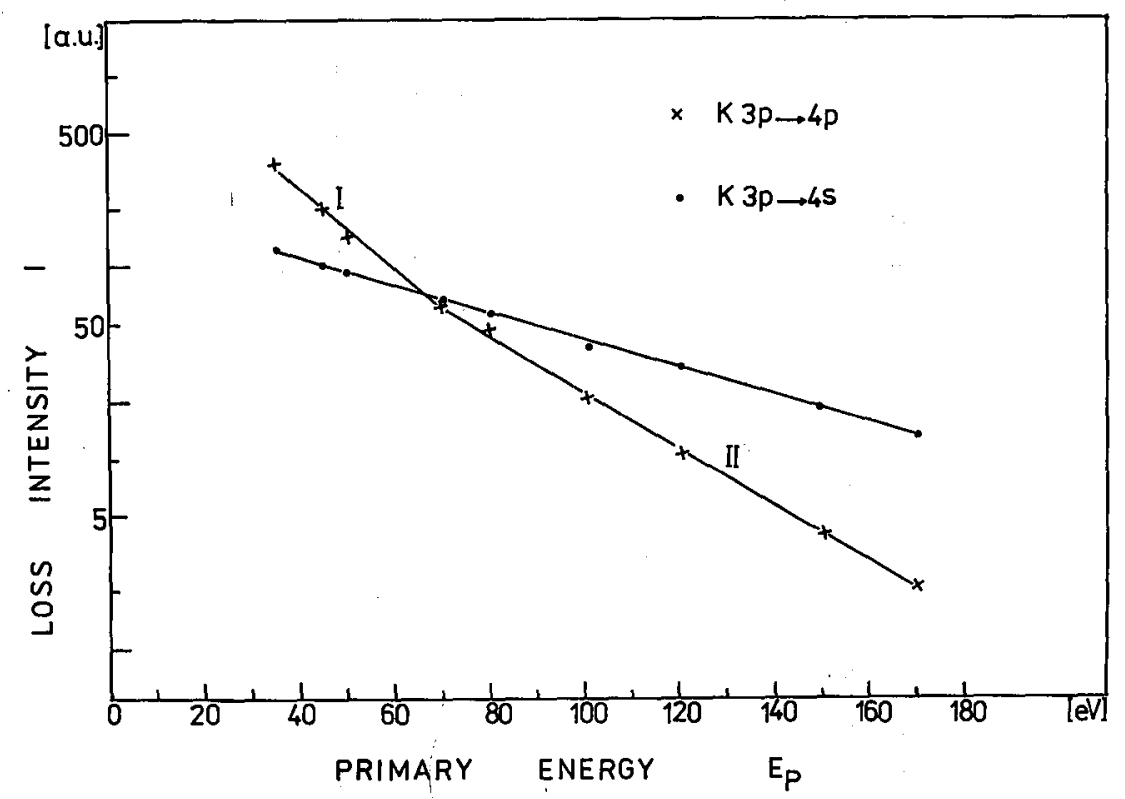

Fig. 11. The loss peak intensity of the $\operatorname{Si}(100) \mathrm{K} 3 p-4 p$ and $\mathrm{K} 3 p-4 s$ transition as a function of the primary electron energy.

[46]. This agreement would be in favour of the ionization model in contrast to the covalent bonding mentioned in the introduction. The $\mathrm{K} 3 p-4 p$ shift, however, is much smaller than the corresponding difference $(2.7 \pm 0.5 \mathrm{eV})$ of the optical excitation. This might be connected with the hybridization discussed above. Up to now there seem to be no published unique results of the core shifts with increasing potassium adsorption.

The interpretation of the relatively small loss at $22 \mathrm{eV}$, growing in intensity with the primary energy, is more difficult. It might be a transition from the $\mathrm{K} 3 p$ orbital into the conduction band DOS maximum of the substrate which would also explain the $E_{\mathrm{p}}$ dependence. The difference of loss and binding energy, $22.0 \mathrm{eV}-18.2 \mathrm{eV}=3.8 \mathrm{eV}$, points to a DOS maximum at about $3.8 \mathrm{eV}$ where at least a maximum at $2.8 \mathrm{eV}$ is known. An alternative explanation may be found in the excitation of the $2 s$ oxygen orbital of contaminated potassium. A corresponding $21 \mathrm{eV}$ loss has been observed for oxygen on the $\mathrm{Cu}(111) \mathrm{Cs}$ surface [44] or a $22 \mathrm{eV}$ loss with the $\mathrm{W}(100) \mathrm{K}$ system [49]. We could not determine a unique connection between the $22 \mathrm{eV}$ loss and the $\mathrm{O}_{2}$ contamination and the $E_{\mathrm{p}}$ dependence seems to favour the above cross-transition interpretation.

The binding energy of the core levels is a sensitive indicator of the adparticle charge state manifested in the so-called chemical shifts observed by XPS, AES and ELS. The K $2 p$ core shift deduced from the spectra of Fig. 9 is displayed in Fig. 12 versus the coverage given by the deposition time. $\mathrm{A}$ change by $1 \mathrm{eV}$ is 


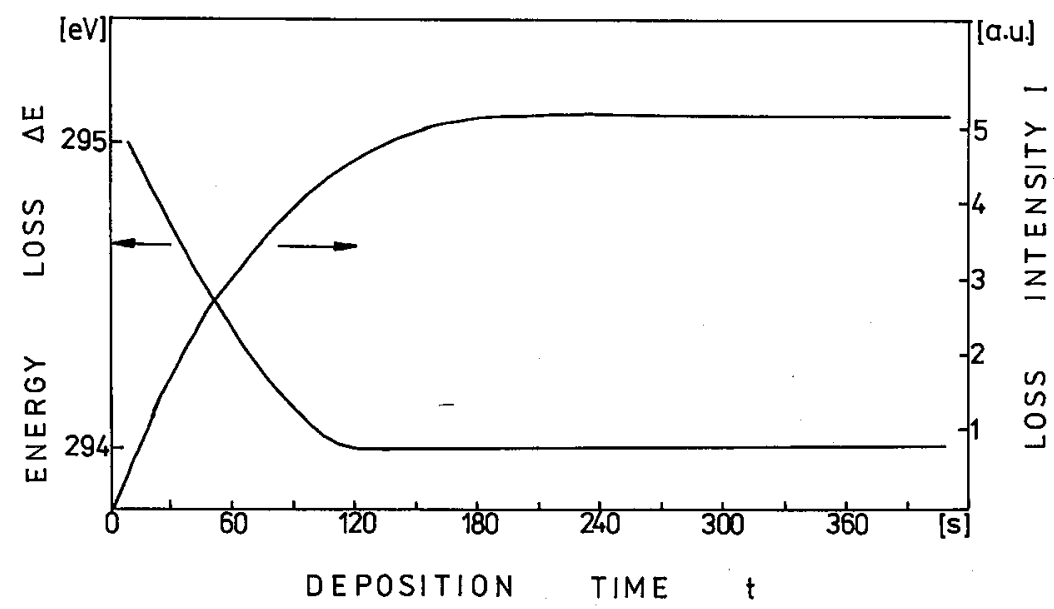

Fig. 12. The ionization or core loss energy of the $\mathrm{Si}(100) \mathrm{K} 2 p$ excitation and the loss intensity as a function of the $K$ coverage at room temperature given by the deposition time.

observed during the first $100 \mathrm{~s}$ while the intensity increases further up to $180 \mathrm{~s}$. Oellig et al. [34] measured by XPS also a K $2 p$ shift of $1 \mathrm{eV}$ up to $0.5 \mathrm{ML}$ for the $\mathrm{Si}(100) \mathrm{K}$ system. A coverage independent charge transfer would create a constant core binding energy. One can conclude, therefore, that the "metallization" of the overlayer takes place beyond the half monolayer coverage while up to this $\mathrm{K}$ surface density the charge transfer to the silicon substrate decreases from a high initial value corresponding to the highest binding energy. Because the $\mathrm{K}$ initial state is again responsible for the excitation the shifts in $\mathrm{K} 3 p$ and $\mathrm{K} 2 p$ of about $1 \mathrm{eV}$ have the same origin, i.e. the charge state of the $\mathrm{K}$ adsorbate.

\subsection{Determination of density of states' features}

We use an EL spectrum simulation program, based on the REELS density of states model and described earlier [50,51], to determine the most probable adsite. By this procedure loss spectra are calculated by a special convolution with the surface densities giving an approximate joint density of states. The simulated loss maximum energies are compared with those of the experimental spectra.

Tochihara [11] and Aruga et al. [16] observed by LEED investigations that the $\mathrm{Si}(100) 2 \times 1$ reconstruction is preserved during potassium deposition. Using this surface structure Ramirez [52] took 4 possible adsites into account for calculations of the surface free energy and the surface density of states. The occupation of one adatom per adsite corresponds to a coverage of 0.5 ML. The "multicenter" Si-K bonding of the chemisorbed potassium at the adsites B leads to a surface density of states (SDOS) which is shown in Fig. 13 where also the main expected transitions are indicated by arrows. We used the available SDOS between -12 and 

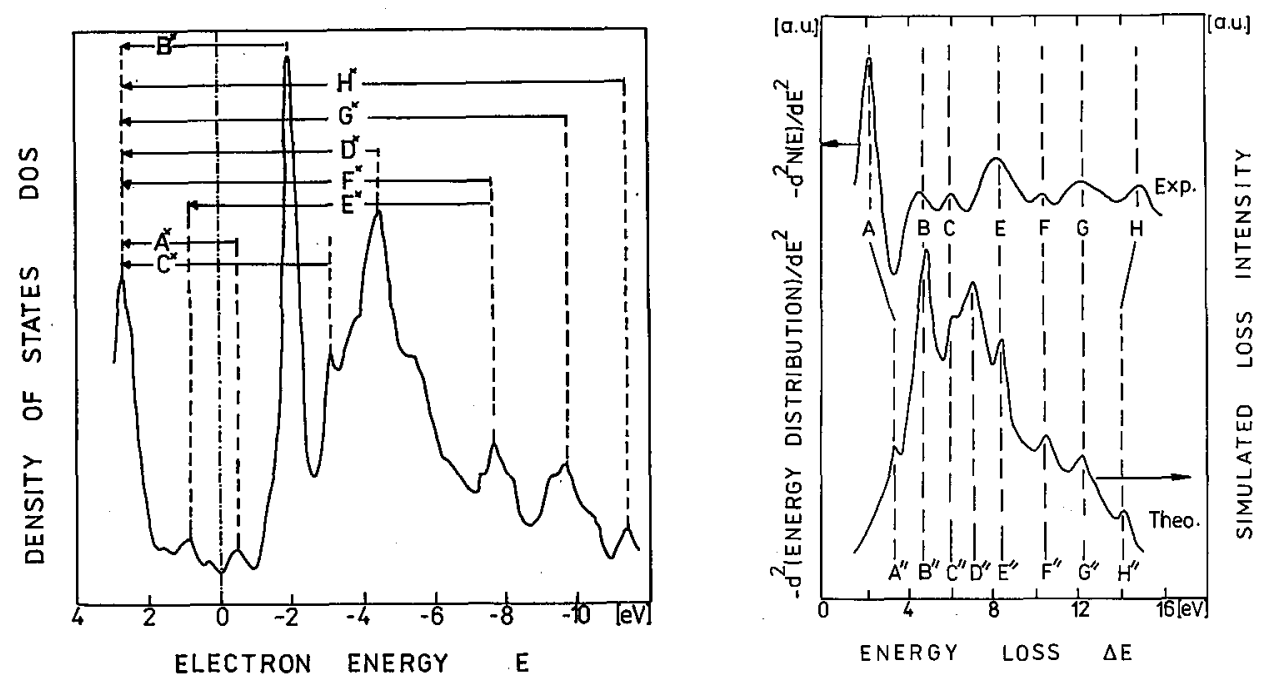

Fig. 13. Total surface density of states for potassium in the $\operatorname{Si}(100) \mathrm{B}$ adsite position calculated by Ramirez [52]

Fig. 14. Comparison of the simulated spectrum according to the DOS for the $B$ adsite occupied by potassium after Ramirez [52] with the experimental second derivative $\mathrm{Si}(100) \mathrm{K}$ spectrum.

$+3 \mathrm{eV}$ to simulate the spectra for the adsite positions $\mathrm{A}$ to $\mathrm{D}$. The most favourable spectrum (Theo.) is reproduced in Fig. 14 and compared with the second derivative experimental curve (Exp.) obtained after $270 \mathrm{~s} \mathrm{~K}$ deposition. We use this coverage for the spectrum comparison because the $K$ peaks at higher energies are clearly manifest only at about ML coverage. Of course, only the positions of the loss maxima can be compared, not the shape of the curves. The $\mathrm{Si}(100) \mathrm{K}$ losses are found to be in favourable agreement with the losses expected for occupation of the $B$ adsites as is obvious from Table II. Ramirez found the highest stability also for the $B$ adsites in contrast to the assumed $A, C$, and D position [52]. If we compare the simulation with the peaks appearing below half ML coverage (Fig. 7) we find, however, that the first adsites to be occupied by potassium should be the $\mathrm{A}$ or pedestal sites. Figure 15 shows the comparison with the simulations for the adsites $\mathrm{A}, \mathrm{C}$, and $\mathrm{D}$. In Table II we also mention the traditional names of the $\mathrm{Si}(100) 2 \times 1$ adsites according to Refs. [10], [53].

We performed an analogous simulation with the $\operatorname{Si}(100) 2 \times 1 \mathrm{~K}$ density of states calculated by Kasowski and Tsai [20]. They choose the "centre of the six-fold hollow site" which corresponds to the A adsite of Ramirez. The results are also 


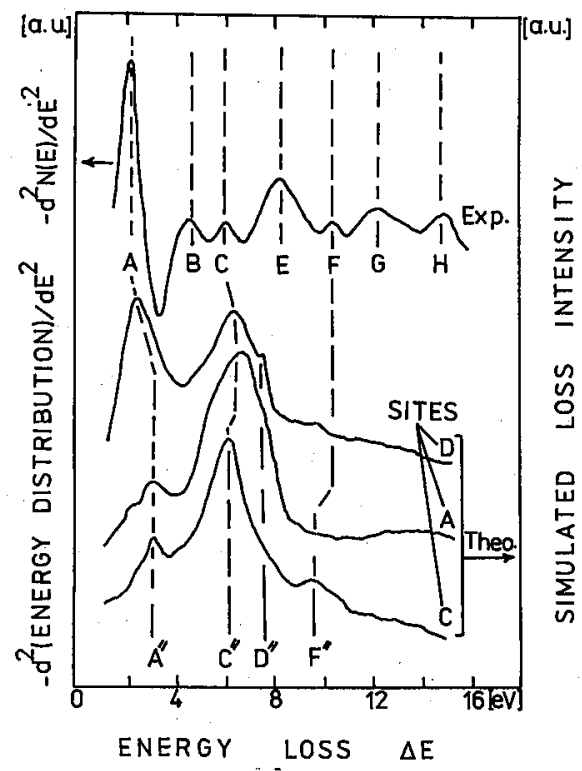

Fig. 15. Comparison of the simulated spectrum according to the DOS for the A, C and $D$ adsite occupied by potassium after Ramirez [52] with the experimental second derivative $\mathrm{Si}(100) \mathrm{K}$ spectrum.

TABLE II

Comparison of experimental ELS results with spectrum simulations using the $\mathrm{Si}(100) \mathrm{K}$ density of states for different $\mathrm{K}$ adatom positions $\mathrm{A}-\mathrm{D}$ calculated by Ramirez [52] and the total $\mathrm{Si} / \mathrm{K}$ SDOS calculated by Kasowski and Tsai [20] corresponding to adsite A.

\begin{tabular}{|c|c|c|c|c|c|c|}
\hline \multirow{4}{*}{ Peak } & \multirow{4}{*}{ Exp. } & \multicolumn{5}{|c|}{ Simulation } \\
\hline & & \multicolumn{4}{|c|}{ Ramìrez } & \multirow{2}{*}{$\begin{array}{l}\text { Kasowski } \\
\text { and Tsai }\end{array}$} \\
\hline & & $\mathrm{A}$ & B & $\mathrm{C}$ & $\mathrm{D}$ & \\
\hline & & pedestal & cave & valley bridge & bridge & (A) \\
\hline $\bar{A}$ & 2.6 & 3.1 & 3.1 & 3.1 & 2.4 & - \\
\hline B & 4.8 & - & 4.8 & - & - & 5.3 \\
\hline $\mathrm{C}$ & 6.4 & 6.7 & 6.3 & 6.6 & 6.3 & 6.7 \\
\hline D & - & - & 7.1 & - & 7.5 & - \\
\hline $\mathbf{E}$ & 8.7 & - & 8.4 & - & - & 8.6 \\
\hline $\mathbf{F}$ & 10.8 & - & 10.4 & 9.8 & - & 10.7 \\
\hline G & 12.6 & - & 12.2 & - & - & 11.8 \\
\hline $\mathrm{H}$ & 15.2 & - & 14.1 & - & - & - \\
\hline
\end{tabular}


given in Table II where by comparison of the losses appearing in both spectra the $B$ adsite of Ramirez is again sligthly favoured. If one combines the $K$ DOS of Ref. [20] above the Fermi level with the Si total DOS below $E_{\mathrm{F}}$ it is obvious that the losses between 4.8 and $10.8 \mathrm{eV}$ can be understood to stem mainly from transitions into the adsorbed potassium DOS maximum at $1.3 \mathrm{eV}$.

\section{References}

[1] I.F. Lyuksyutov, A.G. Naumovets, V.L. Pokrovsky, Dvumernye Kristally (Two-Dimensional Crystals, in Russian), Naukova Dumka, Kiev 1988.

[2] H.P. Bonzel, Surf. Sci. Rep. 8, 43 (1988).

[3] Physics and Chemistry of Alkali Metal Adsorption, Eds. H.P. Bonzel, A.M. Bradshaw, G. Ertl, Mater. Sci. Monographs 57, Elsevier, Amsterdam 1989.

[4] T. Abukawa, Y. Enta, T. Kashiwakura, S. Suzuki, S. Kono, T. Sakamoto, J. Vac. Sci. Technol. A 8, 3205 (1990).

[5] P. Soukiassian, H.I. Starnberg, T. Kendelewicz, Appl. Surf. Sci. 41/42, 395 (1989).

[6] A.N. Andriotis, Phys. Rev. B 42, 9217 (1990).

[7] I.P. Batra, J. Vac. Sci. Technol. A 8, 3425 (1990).

[8] P. Soukiassian, M.H. Bakshi, Z. Hurych, T.M. Gentle, Surf. Sci. 221, L759 (1989);

P. Soukiassian, H.I. Starnberg, in: [3], p. 449.

[9] H. Ishida, K. Terakura, Phys. Rev. B 40, 11519 (1989).

[10] J.D. Levine, Surf. Sci. 34, 90 (1973).

[11] H. Tochihara, Surf. Sci. 126, 523 (1983).

[12] T. Aruga, H. Tochihara, Y. Murata, Phys. Rev. B 34, 8237 (1986).

[13] S. Ciraci, I.P. Batra, Phys. Rev. Lett. 56, 877 (1986).

[14] M.-H. Tsai, R.V. Kasowski, Bull. Phys. Soc. 32, 856 (1987).

[15] E.M. Oellig, R. Miranda, Surf. Sci. 177, L947 (1986).

[16] T. Aruga, H. Tochihara, Y. Murata, Phys. Rev. Lett. 53, 372 (1984).

[17] H. Ishida, N. Shima, M. Tsukada, Surf. Sci. 158, 438 (1985).

[18] T. Kato, K. Ohtomi, Surf. Sci. 158, 505 (1985).

[19] I.P. Batra, S. Ciraci, Phys. Rev. B 37, 8432 (1988).

[20] R.V. Kasowski, M.-H. Tsai, Phys. Rev. Lett. 60, 546 (1988).

[21] Ye Ling, A.J. Freeman, B. Delley, Phys. Rev. B 39, 10144 (1989).

[22] E.F. Greene, J.T. Keeley, M.A. Pickering, Surf. Sci. 120, 103 (1982).

[23] H. Tochihara, Y. Murata, Surf. Sci. 215, L323 (1989).

[24] Ch. Kleint, S. Mahmoud, Surf. Sci. 247, 375 (1991).

[25] D.M. Zehner, R.E. Clausing, G.E. McGuise, L.H. Henkins, Solid State Commun. 13, 681 (1973).

[26] R.E. Clausing, D.S. Easton, G.L. Powell, Surf. Sci. 36, 377 (1973).

[27] S. Nishigaki, M. Ohara, A. Murakami, S. Fukui, S. Matsuda, Appl. Surf. Sci. 35, 121 (1988-89).

[28] J. Hölzl, F.K. Schulte, Work Function of Metals, Springer Tracts Mod. Phys. Vol. 85, Springer, Berlin, Heidelberg 1979, p. 1. 
[29] H.B. Michaelson, J. Appl. Phys. 48, 4729 (1977).

[30] L. Surnev, G. Bliznakov, M. Kiskinova, Solid State Commun. 37, 87 (1981).

[31] J.-L. Desplat, C.A. Papageorgopoulos, Surf. Sci. 92, 97 (1980).

[32] J.-L. Desplat, Proc. 7th Intern. Vac. Congr. and Srd Intern. Conf. Solid Surfaces, Vienna, 903 (1977).

[33] M. Erbudak; T.E. Fischer, Phys, Rev. Lett. 29, 732 (1972).

[34] E.M. Oellig, E.G. Michel, M.C. Asensio, R. Miranda, J.C. Durán, A. Muñoz, F. Flores, Europhys. Lett. 5, 727 (1988).

[35] Y. Enta, T. Kinoshita, S. Suzuki, S. Kono, Phys. Rev. B 39, 1125 (1989).

[36] S. Nishigaki, S. Matsuda, T. Sasaki, N. Kawanishi, Y. Ikeda, H. Takeda, Surf. Sci. 231, 271 (1990).

[37] T. Kloos, Z. Phys. 243, 225 (1973).

[38] A.V. MacRae, K. Muller, J.J. Lander, J. Morrison, J.C. Phillips, Phys. Rev. Lett. 22, 1048 (1969).

[39] S. Andersson, V. Jostell, Faraday Diss. Chem. Soc. 60, 255 (1975).

[40] V. Jostell, Surf. Sci. 82, 333 (1979).

[41] H. Tochihara, Y. Murata, J. Phys. Soc. Japan 51, 2920 (1982).

[42] Ch. Kunz, Z. Phys. 196, 311 (1966).

[43] H. Fellenzer, Z. Phys. 165, 419 (1961).

[44] S.A. Lindgren, L. Walldén, Phys. Rev. B 22, 5967 (1980).

[45] G. Brodèn, H.P. Bonzel, Surf. Sci. 84, 106 (1979).

[46] C.E. Moore, Natl. Bur. Stand. Circ., 467 (1949).

[47] R. Ludeke, A. Koma, Phys. Rev. Lett. 34, 817 (1975).

[48] J.P. Muscat, D.M. Newns, Surf. Sci. 84, 262 (1979).

[49] K.G. Voigt, Dissertation, KMU Leipzig 1982, unpublished.

[50] Ch. Kleint, Vacuum 36, 267 (1986).

[51] Ch. Kleint, M. Funke, R.D. Tomlinson, Appl. Phys. A, Solids Surf. 46, 137 (1988).

[52] R. Ramìrez, Phys. Rev. B 40, 3962 (1989).

[53] Ye Ling, A.J. Freeman, B. Delley, Surf. Sci. 239, L526 (1990). 